
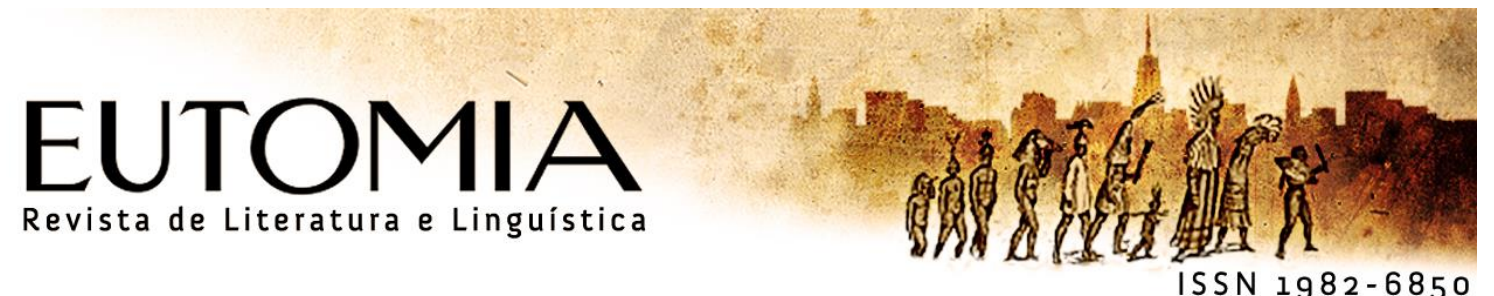

\title{
La noche de Max Estrella: claves estéticas del esperpento en Luces de bohemia
}

\author{
Xaquín Núñez Sabarís ' (Universidade do Minho)
}

\begin{abstract}
Resumen: Este trabajo responde al desafío de hacer comprensible uno de los textos canónicos más complejos e icónicos de la literatura española, desde el punto de vista estético: Luces de bohemia. Para ello, se profundizará en los fundamentos artísticos, culturales y teatrales de manejados por Valle-Inclán en este texto dramático, fundacional de su concepto de esperpento. Este drama vanguardista ofrece una clara impugnación de los códigos culturales de la época, así como una expresionista imagen del Madrid de los años 20, a través del juego de espejos y luces que ofrece el drama. Se analizarán, pues, las claves discursivas de la obra, el it inerario escénico y conceptual del protagonista, cuyo errante y visionario viaje es el eje que hace mover esta poliédrica rueda sobre la que gira Luces de bohemia.
\end{abstract}

Abstract: This work responds to the challenge of making understandable one of the most complex and iconic canonical texts of Spanish literature, from the aesthet ic point of view: Lights of bohemia. To do this, the artistic, cultural and theatrical fundamentals handled by Valle-Inclán will be deepened in this dramatic text, which is the foundational concept of the grotesque. This avant-garde drama offers a clear challenge to the cultural codes of the time, as well as an expressionist image of Madrid in the 1920s, through the play of mirrors and lights offered by the drama. We will analyze, then, the discursive keys of the work, the scenic and conceptual it inerary of the protagonist, whose errant and visionary journey is the axis that makes this polyhedral wheel move on which Luces de bohemia turns.

\section{Madrid, años 20}

Luces de bohemia ocupa, sin lugar a dudas, un lugar privilegiado dentro de la obra literaria de Valle-Inclán. Así lo manifiestan, ochenta años después de su muerte y liberados los derechos de autor de su obra, la notable cantidad y calidad de trabajos 
críticos sobre este texto. Las ediciones de Míguez Vilas (VALLE-INCLÁN, 2017a), Caudet (VALLE-INCLÁN, 2017b), Iglesias Feijoo (VALLE-INCLÁN 2017C), Aznar Soler (2017) o Núñez Sabarís (VALLE-INCLÁN, 2018) acreditan el interés, desde el punto de vista editorial y comercial, por este drama valleinclaniano. Se completa la actividad cultural, en torno a esta obra, con el montaje del Centro Dramático Nacional, cuyo estreno se produjo el cuatro de octubre de 2018 en el Teatro María Guerrero, de Madrid.

De modo que esta pieza teatral no ha perdido actualidad, desde que fuese publicada en el año 1920, por entregas, en la revista España. Esta primera edición ya se anunciaba con el subtítulo de "esperpento" e incluía la escena en que Max Estrella, su protagonista, enunciaba la nueva estética teatral, que había de quedar como una marca indeleble del genio dramático de don Ramón del Valle-Inclán. En 1924 el autor publicaba por primera vez en libro el texto y añadía tres escenas con respecto a la primera versión (las actuales II, VI y XI). Con ellas se completaba un total de quince, que compondrían la versión definitiva de Luces de bohemia. No resulta casual, como luego se analizará, el número total de las escenas, además, su contenido reforzaba la orientación política del esperpento, dotando de una práctica más consistente la intencionalidad teórica esbozada en la edición en prensa. ${ }^{1}$ El episodio en la librería de Zaratustra, con alusiones al clima prerrevolucionario (escena II), la represión aplicada al preso catalán (escena $\mathrm{VI}$ ) o la violencia desatada en las calles (escena XI) reflejaban el Madrid conflict ivo de los años 20, antesala de la dictadura de Primo de Rivera (19231931), satirizada también en alguno de los esperpentos de la trilogía Martes de Carnaval. El Madrid absurdo y hambriento de este período, materia prima de la estética esperpéntica, que refleja, consiguientemente, la crisis social y económica mundial que se abre después de la Primera Guerra Mundial y que eclosiona en este período. La ciudad, los contrastes de luz y sombra, la ceguera, la risa y el Ilanto para

\footnotetext{
${ }^{1}$ Cardona y Zahareas (2012, p. 106) analizan la transformaciones del texto de la primera versión en prensa en la edición de 1924. Señalan la intensidad dramática de las tres escenas introducidas. En opinión de Aznar Soler (2000: 347) la adición de estas tres escenas completa en la práctica la teoría esperpéntica de Valle, todavía verde en 1920.
} 
superar una situación trágica nos ponen en la senda del escepticismo cultural de este período, de una modernidad paradójica.

Es imposible decir con precisión cuándo se puede comenzar a hablar de la existencia de dos modernidades distintas y en franco conflicto. Lo que es cierto es que en algún momento de la primera mitad del siglo XX se produce una irreversible separación entre la modernidad como un momento de la historia de la civilización occidental producto del progreso científico y tecnológico, de la revolución industrial, de la economía arrolladora y los cambios sociales del capitalismo- y la modernidad como un concepto estético. Desde entonces, la relación entre las dos modernidades ha sido irreductiblemente hostil, pero no sin permitir, e incluso estimular, una variedad de influencias mutuas en su cólera por la mutua destrucción. (CALINESCU, 1991, p. 51)

La contradictoria relación existente entre la modernidad social y artística, descrita por Calinescu, se puede fácilmente evidenciar en la adjetivación del Madrid de Luces de bohemia, realizada en la nota que abre la obra: "brillante, absurdo y hambriento". La brillantez intelectual, pero también modernamente lumínica, sitúa la obra en ese importante juego de luces que la noche madrileña nos ofrece como cobijo de una bohemia, tan lúcida como absurda:

Los esperpentos de Valle-Inclán tienen mucho en común con el teatro absurdo y con la literatura existencialista en general. En todas estas obras lo absurdo anda bordeando el humor y la angustia a un mismo tiempo, es decir, la inquietud también provoca risa y generalmente señala alguna disparidad de la que uno puede "reírse" o indist intamente cabe "tomar en serio". Pues hay partes de nuestro mundo que son evidentemente absurdas y nuestro encuentro con lo absurdo, aunque con frecuencia sea excesivamente doloroso, tiene al mismo tiempo sus aspectos cómicos. (CARDONA; ZAHAREAS, 2012, p. 56)

El protagonismo que la ciudad adquiere en el siglo XX revela hasta qué punto la nueva urbe recoge las profundas transformaciones sociales, políticas, científicas y culturales del nuevo siglo. En 1920, Madrid es una gran metrópoli, con un significativo aumento de su población: "Estas alusiones precisas y reales indican que el mundo dramát ico de Luces de bohemia desdobló el Madrid histórico de principio de los veinte, precisamente en la época en que la capital alcanzó la categoría de metrópoli. En 1920 
Madrid contaba con 750.896 habitantes, un aumento del $50 \%$ sobre la población de 1910" (DOUGHERTY, 2003, p. 163). La obra, de hecho, refleja el carácter poliédrico de la ciudad y la dimensión de la capital como importante centro cultural, con sus libreros, prensa literaria, poetas modernistas y bohemios. ${ }^{2}$ La ciudad es un elemento fundamental, por lo tanto, en el arte de este período, ya que en este espacio urbano se concentra una parte importante de la obra dramática de Valle-Inclán, cuyo análisis impone una metodología en la "frontera entre el estudio del teatro valleinclaniano y la disciplina que sitúa la ciudad en el centro del sistema moderno de producción cultural" (DOUGHERTY, 2003, p. 160).

Por lo tanto, la urbe del siglo XX se impone como una realidad que atrae por igual a creadores y lectores. Cómo se representa y construye esta realidad, problematizada desde su enunciación, es un aspecto que se aborda en Luces de bohemia al dramatizar el Madrid real de este período. Desde inicios de siglo se había convertido en un importante núcleo de producción cultural, y allí se había dirigido el joven Valle-Inclán en 1896, para aprovechar el importante impulso cultural de la capital, en busca de profesionalización y notoriedad literaria. ${ }^{3}$ Incluso resulta posible establecer algún paralelismo en las tensiones entre creador y librero, reflejadas en la librería de Zaratustra, con los sinsabores literarios que el novel Valle-Inclán había sufrido a su llegada a Madrid:

Querido D. Cristóbal: Yo, hasta ahora, jamás he ganado cosa alguna con mis libros. De los primeros he vendido hasta cinco o seis ejemplares; de los últimos vendo algunos más, pero nunca lo bastante para costear las ediciones.

Todas mis esperanzas están puestas en un libro que publicaré dentro de algunos días: La sonata de Primavera. Seguramente se venderán algunos centenares de miles, y con el dinero que me dejen, pienso restaurar los castillos del Marqués de Bradomín y comprarme un

\footnotetext{
2 En Salaün; Serrano (1991) se analizan las condiciones e instituciones culturales y la expansión de la cultura urbana en torno al 1900.

3 "La incorporación a un mercado libre e industrializado, en que la obra de arte adquiere, por tanto, valor de producto para el consumo, permite a los escritores superar la dependencia casi absoluta que hasta ese momento habían mantenido respecto a las grandes instituciones del mecenazgo, especialmente a partir de la promulgación de leyes que reconocen la propiedad intelectual. Este hecho confiere a los autores derechos específicos sobre sus obras frente a los demás participantes en la producción, esto es, editores, impresores y distribuidores" (VILLARMEA ÁLVAREZ, 2009, p. 650).
} 
elefante blanco, con una litera dorada, para pasearme por La Castellana. (VALLE-INCLÁN; VALLE-INCLÁN, 1994, p. 13).

De modo que, en Luces de bohemia, Valle-Inclán le da una categoría estética a la ciudad, en la senda del panorama cultural y artístico de su tiempo. La dimensión plástica y la apuesta rupturista se asocian con la literatura, el teatro y el cine de entreguerras. Estas claves, por ejemplo, también son verificables en una obra que guarda cierta proximidad con el drama que analizamos. El protagonismo de la urbe y el poso trágico y cómico de Chaplin en Luces de ciudad invitan a poner en relación ambas obras como expresiones de una ciudad de luces y sombras, de héroes nómadas y cegueras con un fuerte carácter simbólico. La comparación entre drama y filme pone, además, de relieve la dimensión visual -y preclaramente cinematográfica- ${ }^{4}$ del teatro de Valle. La influencia de la pintura en el autor muestra su predilección por el efecto visual y plástico, bien reflejado en las acotaciones de su teatro, que supone también una cierta poét ica del silencio, que lleva a cuestionar, dentro de los impulsos vanguardistas del momento, los discursos hegemónicos de la época y la capacidad expresiva de la literatura:

Como en tantas ocasiones, las artes plásticas son la vanguardia del problema y las que logran exhibirlo mejor. El cubismo, el arte abstracto después, la música de Schöenberg, de Darius Milhaud y de Alban Berg. Finalmente, el cine. Es el cine el gran introductor en la conciencia actual de este sentido de la discont inuidad, del azar, de lo fragmentario. [...]

Y podríamos hacer más largo y representativo el desfile. Visión fragmentaria de la vida, acosada de momentaneidad. Nada más explícito que ese hueco, lleno de sugestiones, que se motiva en la fila de fantoches, cuando uno de ellos abandona la habitación.

Y todo eso es cine, está visto cinematográficamente. Es precisamente su febril exaltación del movimiento (gestos, muecas, etc.) lo que le diferencia y caracteriza. (ZAMORA VICENTE, 1969, p. 157-158)

Luces de bohemia deja, pues, entrever la fascinación de Valle por el cine, como la gran transformación escénica que se avecinaba:

\footnotetext{
${ }^{4}$ Sobre la relación de Valle-Inclán y el cine, véase Zamora Vicente (1969), Barreiro (1995), Paz Gago (2000) o Fernández (2001).
} 
Y a los Cinemas, ya lo creo que voy. Ese es el Teatro nuevo, moderno. La visualidad. Más de los sentidos corporales; pero es arte. Un nuevo Arte. El nuevo arte plástico. Belleza viva. Y algún día se unirán y completarán el Cinematógrafo el Teatro por antonomasia, los dos Teatros en un solo Teatro. $Y$ entonces se podrá concurrir, perder el tiempo en el Teatro. (DOUGHERTY, 1983, p. 168).

\section{El itinerario de Max Estrella}

Luces de bohemia es una obra fundamentalmente itinerante. Dentro de la evolución contemporánea hacia un arte más espacial, la acción dramática transcurre en un solo día. ${ }^{5}$ El momento en que Max Estrella sale de su casa en la escena I, en la hora crespuscular, hasta que regresa borracho al amanecer para morir en el mismo portal, en la escena XII. Se añaden tres escenas más, que representan el grotesco velorio del protagonista, la conversación, de tintes románticos, entre el Marqués de Bradomín y Rubén Darío, y concluye en la taberna de Pica Lagartos, con otro guiño a la mala estrella de Max: el décimo de la lotería robado por Don Latino había resultado premiado. $^{6}$

El it inerario de Max se organizan en las diferentes estaciones que componen cada uno de los cuadros escénicos de la obra y configuran un recorrido laberíntico círculo infernal llega a decir el protagonista-, expresión del sincret ismo cultural en que Valle apoya su propuesta teatral: el círculo dantesco, los paralelismos formales y semióticos con el viacrucis, los guiños homéricos y la diversidad de espacios que reflejan el descenso a los infiernos de Max en la heterogeneidad de escenarios del Madrid nocturno: tabernas, busconas, despachos ministeriales, redacción de periódicos afirman la ciudad como la gran protagonista de esta tragedia:

\footnotetext{
5 Nos referimos en este caso, a la que ocupa las doce primeras escenas. Valle-Inclán sigue, en cuanto a la organización temporal, las convenciones aristotélicas de tragedia. De modo que, como se verá en adelante, Luces de bohemia se equilibra entre la noción tradicional y vanguardista de este género teatro.

${ }^{6} \mathrm{Si}$ el it inerario de Max se organiza circularmente, la últ ima escena crea también un paralelismo con la primera. La mala suerte del poeta con que se inicia la obra (se cancelan sus colaboraciones en el períodico) se proyecta en esta fortuna póstuma. Por otro lado, Claudinita profet iza en el primer acto, a propósito de la salida de su padre con Don Latino, que acabará en la Taberna de Pica Lagartos.
} 
El primer esperpento es una presentación sistemática del Madrid de la época y utiliza con mucha exact itud como trasfondo la España de entre 1900 y 1920. Pero por medio de los periódicos y revistas de la época, podremos comprobar que el cuadro de la bohemia madrileña que nos presenta Valle-Inclán es en su mayor parte verificable y que mucho del contenido histórico es auténtico. En pocas palabras, Luces puede considerarse como un documental bastante exacto; ValleInclán incluye una cantidad sorprendente de detalles históricos y sucesos, de reuniones, de citas periodísticas, de tópicos populares, de frases usadas por entonces en el argot y sobre todo nos da el aspecto físico de la ciudad y los sucesos políticos reales. (CARDONA; ZAHAREAS, 2012, p. 83)

Entre las referencias culturales que configuran esta construcción estética de Madrid, es preciso destacar las evocaciones bíblicas del recorrido de Max, ya no sólo por las similitudes entre la enunciación artísticamente redentora del esperpento, sino por las semejanzas entre el recorrido de Max y la Pasión. Es, no obstante, un recurso habitual en Valle recurrir a símbolos cristológicos (por ejemplo el pelícano en los grabados de sus obras) $^{7}$ y a la potencia performativa de la narrativa evangélica, señalada, por ejemplo, en el desenlace de Divinas palabras. En Luces de bohemia son importantes las similitudes con el texto del viacrucis, tanto por las quince escenas, que se corresponden en número con las estaciones bíblicas, como por la estructura de las mismas. El tan comentado momento anticlimático de la obra, cuya acción dramática concluye en la escena XII, con la muerte de Max, anticipándose en tres actos al final del drama, se corresponde con la misma estación en que se produce la crucifixión. Esta disonancia, entre el momento trágico de la muerte de Cristo y el grotesco deceso de Max (ambos en el paso XII de ambas estaciones) señala el punto de encuentro esperpéntico, como veremos, dentro de la tragedia distorsionada, que degrada y deforma los soportes culturales y discursivos sobre los que se apoya.

La expresión grotesca no compromete, sin embargo, el anuncio redentor del nuevo género: el esperpento. Dougherty (2012) apunta al mito de Orfeo como germen

\footnotetext{
7 Interpretación ofrecida por Jesús Rubio en su conferencia Ángel Vivanco y Ramón del Valle-Inclán: las artes del libro, el 22 de noviembre de 2016 en la Universidade de Santiago de Compostela, dentro del ciclo de conferencias organizado por la Cátedra Valle-Inclán en el programa conmemorat ivo, Valle-Inclán. 150 Aniversario (1866-2016).
}

Eutomia, Recife, 22(1): 201-218, Dez. 2018 
de la nueva estética (destruir para crear), ${ }^{8}$ de modo que la muerte de Max tiene, consecuentemente, una voluntad redentora: la destrucción y renovación de los caducos discursos literarios, periodísticos, históricos.... Sin embargo, la fuerza dramática y heroica del momento y de Max Estrella está desactivada desde el inicio por la desvalorizada figura del héroe, un escritor menor de "odas y madrigales", lo cual señala la incapacidad de introducir un agente enunciador y hegemónico en el caos cultural que es el Madrid de los veinte. Su anticlimático fallecimiento, contrarrestado con tres escenas más, resulta consecuente con su identidad oximorónica (Cardona y Zahareas (2012) o Aznar Soler (2000)) y, de nuevo, añade el elemento paródico con la narrativa evangélica, dada la similitud entre las tres últimas escenas y los episodios del relato bíblico: las reacciones post-mortem, de Madama Collete y Claudinita rememoran la visita de María y María Magdalena al sepulcro vacío de la decimocuarta estación de la pasión

La urbe se enuncia, pues, en su dimensión problemática y problematizada. De esta perspectiva surge su condición laberíntica que encierra a los personajes que la transitan. El carácter críptico de la ciudad se expresa en esta estructura circular que parece atrapar al personaje, cuyo resultado final es su fracaso, si bien redentor en Luces de bohemia. Su legado artístico -la formulación del nuevo arte: el esperpentosólo llega con su muerte, ya que no consigue hilar un discurso hegemónico ni transmit ir una explicación lógica y coherente de la realidad que habita.

La conjunción, por lo tanto, de la ciudad y un protagonista it inerante remite a la figura del flâneur, muy presente en los textos literarios desde los últ imos años del XIX: de Baudelaire a Martí es una figura imprescindible de la modernidad literaria, que se expresa en la crónica periodíst ica. ${ }^{9}$ Sin embargo, frente a la clarividencia del flâneur

\footnotetext{
8 "Como Orfeo, Valle insistió en no desvincular el arte de la vida. Parte integral de la vida, el arte nace, florece, envejece y muere, renovándose en cada iteración sucesiva (si aparecen jóvenes decididos a hacer su arte en vez de la generación anterior). Por tanto, la renovación del arte, igual que ocurre en otras dimensiones de la vida, no es posible sin la destrucción violenta de formas ya caducas. Crear es destruir (DOUGHERTY, 2012, p. 138).

9 "En la prosa de ideas, el modernismo avaló la presencia de una aportación fundamental, la crónica, como género de la modernidad. El lugar físico de la crónica es el periódico: asume su prisa, la comunicación entrecortada e incompleta, la fugacidad propia de la impresión que nos transmite, pero también hace suyas las contrapartidas más favorables porque el periódico asegura la difusión y realza el valor de la firma (o del seudónimo bien elegido).
} 
convencional, la mirada que arroja este poeta ciego no sólo no servirá para aclarar el panorama social, político y cultural, sino que proyectará una imagen paródica, absurda y grotesca de dicho espacio. De modo que Luces de bohemia no deja de ser una crónica invert ida del Madrid de entonces.

Por lo tanto, si ciudad y flâneur se const ituyen como elementos característicos de la modernidad, Luces de bohemia es una obra inequívocamente moderna. Sin embargo, en el comportamiento de Max no existen atisbos de la racionalidad y clarividencia del detect ive flaneurístico. Muy por el contrario, su discurso se presenta, a menudo, como una secuencia caótica, fragmentada o silenciada. En consecuencia, su comportamiento como flâneur pone de relieve la crisis discursiva de la modernidad, que este drama evidencia.

\section{Max Estrella y la crisis de la modernidad}

El descenso a los infiernos de Max muestra los conflictos e injusticias sociales presenciados por el protagonista, ocasionando una queja de alto valor humano, pero también una ácida diatriba contra los discursos imperantes: la literatura, la prensa, el poder político... que señalan la necesidad de una regeneración moral y estética, que rompa con los presupuestos socio-culturales hasta ese momento vigentes. Esta regeneración del discurso literario está en la base de la teorización del esperpento.

Asimismo, la integridad moral del protagonista, sobresaliente si se compara con Don Latino, queda en entredicho al contrastar su visionario discurso con la aceptación del soborno del ministro o su inacción ante las míseras condiciones en que viven su esposa e hija.

Aun teniendo en cuenta las contradicciones señaladas, la voz de Max es, pese a todo, de las pocas conciencias críticas existentes en ese Madrid "absurdo, brillante y

Pero es imposible definir el género sin el otro elemento esencial: su carácter de escritor personal, de experiencia vivida, más aún, y que remite al capricho, la inclinación el merodeo impune de un yo que se exhibe (y se oculta) ante sus lectores, a medio camino entre el cuento y la memoria personal". (MAINER, 2010, p. 37).

Eutomia, Recife, 22(1): 201-218, Dez. 2018 
hambriento" en el que se desarrolla el drama. A este respecto, resulta especialmente significat iva la escena undécima:

Llega un tableteo de fusilada. El grupo se mueve en confusa y medrosa alerta. Descuella el grito ronco de la mujer, que al ruido de las descargas, aprieta a su niño muerto, en los brazos.

LA MADRE DEL NIÑO. -iNegros fusiles, matadme también, con vuestros plomos!

Max.-Esa voz me traspasa.

LA MADRE DEL NIÑO.- ¡Que tan fría, boca de nardo!

Max.- ¡Jamás oí voz con esa cólera trágica!

Don Latino.- Hay mucho de teatro.

Max.- Imbécil.

(VALLE-INCLÁN, 2018, p.80)

Es preciso poner en relación la emoción que la voz trágica de la mujer suscita en Max con el desafecto con que se expresa ante los discursos imperantes de la prensa o la literatura, enunciados tras la muerte del anarquista catalán ${ }^{10}$ y tras el estallido de la represión ("Canallas. Todos. Y los primeros nosotros, los poetas" [VALLE-INCLÁN 2018: 79]). También el juego con metáforas de naturaleza teatral "trágica", "mojiganga", "farsa" que se suceden en la escena y que preparan el terreno para la escena XII. ${ }^{11}$ Las críticas a la prensa canalla, al acomodaticio lenguaje literario focalizan una importante crítica y el cuestionamiento de las grandes narrativas, que habían constituido el eje político y cultural de la revolución burguesa decimonónica. Es, precisamente, en esta crisis, todavía cuestionada y rebatida en los moldes modernos, donde Lyotard (1989, p. 12) sitúa el giro posmoderno, que se nutre de la quiebra epistemológica que retrata el arte moderno:

Simplificando ao extremo, considera-se que o «pós-moderno» é a incredulidade em relação às metanarrativas. Esta é, sem dúvida, um

\footnotetext{
10 "El Preso.- Van a matarme... ¿Qué dirá mañana esa prensa canalla? Max.- Lo que le manden" (VALLE-INCLÁN. 2017, p. 109).

11 "Porque una situación trágica, la violencia represora de un poder que asesina impunemente con premeditación y alevosía, queda justificada moralmente por la mayoría de una sociedad envilecida e insensibilizada. Así, para don Latino "hay mucho de teatro" en lo que Max estrella está sintiendo, conmovido e impotente, como la "cólera trágica" de una madre desesperada. La mayoría social, embrutecida y alienada, es insensible ante la tragedia de la realidad histórica y es entonces, precisamente entonces, cuando Max Estrella expresa con absoluta claridad la profundidad de su dolor y la desesperación de su impotencia. (AZNAR SOLER, 2000, p. 351)
} 
efeito do progresso das ciências, mas este progresso, por sua vez, presupõe-na. Ao desuso do dispositivo metanarrativo de legitimação corresponde especialmente a crise da filosofia metafísica e da instituição universitária que dela dependia. A função narrativa perde os seus functores, o grande herói, os grandes périplos e o grande objectivo.

Cont inúa todavía Lyotard (1989, p. 13) afirmando que "a sua legit imação (das grandes narrativas), tanto em matéria de justiça social como de verdade científica, adviria da opt imização das performances do sistema, da eficácia".

El contraste moral entre el grito inarticulado de la madre del niño muerto, que sobrecoge a Max, y la ineficacia de las grandes narrativas del campo periodístico y literario remiten, por lo tanto, a la dirección apuntada por Lyotard. Incluso Don Lat ino, al hacer mención a la teatralidad de la mujer, parece advert ir mejor que Max la pérdida de trascendencia discursiva y desactiva la fortaleza moral del grito, exagerando sus capacidades performativas:

Lo que Max aprecia en la voz de la madre es el sufrimiento trágico en su estado puro. Pero igualmente importantes, para su educación cívica y poética, son los comentarios de los demás. (...) Una voz trágica, una víctima inocente, una alusión a la teatralidad del dolor, toda está preparando la escena para que Max reflexione sobre la insuficiencia del género trágico para captar la crisis de la sociedad española moderna. (DOUGHERTY, 2008, p. 59; 471)

El juego semántico de términos teatrales plantea la fuerza dramáticamente performativa del grito, en oposición a la retórica declamativa y comercial en que se había convert ido la escena teatral del momento. Si la crónica modernista se basaba en la lucidez racional de su autor, Luces de bohemia parece apuntar hacia un contexto más posmoderno: las grandes narrativas han entrado en crisis y un desgarrador grito se impone a la necedad literaria del momento.

Es esta literatura renovada la que Valle-Inclán persigue en Luces de bohemia limpiando su estét ica de toda flaccidez retórica. Se sitúa, en ese sentido, en la pulsión vanguardista por añadir un connotativo, autónomo y subversivo signo lingüístico, sugerido en el esperpento, una vez que persigue una estética deformadora, como alternat iva a la invalidez representativa de las convenciones literarias habidas hasta el 
momento. Luces de bohemia asume el experimentalismo de la vanguardia y prosigue con los propósitos expresados en el prólogo a Los cuernos de Don Friolera, tan acorde con las teorías orteguianas acerca de la deshumanización del arte (ORTEGA 1987). Un buen reflejo de ello, es la identificación desconcertante entre el Madrid real y el espacio fict icio de Luces de bohemia:

Al examinar de cerca los itinerarios de Luces de bohemia, voy a atender; en primer lugar, a su representación y a tal fin voy a partir del siguiente postulado general: el teatro ha explotado y explorado lo que David Harvey (1990) ha llamado "el sentido de lugar" Desde esta perspectiva el teatro moderno ha generado en el espectador dos tipos de reacción frente a los espacios dramáticos, que Fernández Cifuentes (2003) explica en términos que resultan aplicables también a Valle-Inclán: una, el confort ante localizaciones tranquilizadoras, espacios dados y reconocibles; la otra, un singular desasosiego, la ansiedad que suscita toda posibilidad de desorientación espacial. (SANTOS ZAS, 2007, p. 189)

Parece, por consiguiente, que Valle-Inclán sólo se adentró en el drama urbano en el momento que diseñó una estética adecuada para ello; de ahí las múltiples asociaciones -volviendo a la cita inicial de Dougherty- entre estética (esperpento) y representación urbana.

En suma, Valle-Inclán cuestiona unas metanarrativas incapaces de reflejar el sentido trágico que asolaba a la sociedad moderna. Sólo que, a diferencia del escepticismo que adoptará la estética posmoderna, propone una alternativa que supere la parálisis representativa: el esperpento.

\section{El esperpento y la estética deformada}

Valle-Inclán desea reflejar una realidad profundamente trágica, pero para ello no puede utilizar los patrones clásicos de la tragedia, ya que esta se ha vuelto retórica y ha perdido su fuerza performativa, tal como se ha señalado. Necesita una estética que sorprenda al lector-espectador, que lo inquiete, subvirtiendo sus códigos culturales, su horizonte de expectativas, que sean el motor para mover las conciencias 
de quienes languidecen en el teatro burgués de principios del XX. ${ }^{12}$ Por tal motivo, esta tarea gira en torno a la conocida escena XII de Luces de bohemia en la que Max muere enunciando la teoría del esperpento, potenciada por los rasgos expresionistas y grotescos enunciados. Se afianza la duplicidad de un personaje, cuya muerte evoca a los héroes trágicos, pero cuya caracterización remite a un poeta menor $y$ contradictorio, que nos deja como última estampa una mueca grotesca.

En Luces de bohemia, como se ha apuntado anteriormente, se hallan elementos que apuntan hacia una superación de la estética moderna, a través de la incorporación de códigos artísticos, que rompen con la norma dramática imperante en el tiempo de Valle. Las referencias culturales sobre las que se construye Max Estrella parecen remitir inicialmente a un imaginario de estilización literaria donde el protagonista constituiría un referente ético. ${ }^{13}$ Incluso su muerte, imaginando el Paris "fin de siècle" y anticipando la teoría del esperpento, apunta sin lugar a dudas a su condición de héroe. Sin embargo, a lo largo de la obra, se va socavando la dimensión heroica del protagonista. Frente al excelso poeta que cabría esperar, la primera acotación aclara que nos hallamos ante un escritor "de odas y madrigales". Asimismo, el final climático que se origina con la muerte de Max, propio de una tragedia convencional, queda desactivado con tres escenas posteriores, que relajan la tensión dramát ica y cuestionan el protagonismo trágico del personaje: ${ }^{14}$

La convencional escena de «la trágica muerte del héroe», ya ironizada en Romance de lobos, recibe un tratamiento aún más

\footnotetext{
12 "Así la trágica mojiganga es una invención valleinclaniana pero resulta llena de actualidad, limitada a una circunstancia histórica y, por eso, se hace símbolo eficaz de un grotesco, desmantelado y errante carnaval de la historia española. La técnica utilizada es la de tomar la acción desde varios ángulos, como se hace con una cámara de cine: cada escena de la acción central -la penuria, la borrachera, las discusiones, la detención, las quejas y la muerte de Max- contiene a la vez una partícula del caos político y así el plano principal de Max y su bohemia está unido teatralmente al trasfondo de las calamidades nacionales". (CARDONA; ZAHAREAS, 2012, p. 89)

13 Se ha apuntado la similitud entre Max Estrella y el poeta Alejandro Sawa: "Los paralelismos entre Max Estrella y Alejandro Sawa saltan a la vista: los dos son ciegos y andaluces; casados con mujeres francesas y padres de sendas hijas. Lo que no cabe esperar es una dramatización fácil y mimética de la biografía de Sawa, sino una interpretación del personaje y del mundo de la bohemia heroica que representa." (RUBIO JIMÉNEZ, 2006, p. 118). Véanse también los estudios de Aznar Soler (2017) e Iglesias Feijoo (VALLE-INCLÁN, 2017c).

${ }_{14}$ "Contra la convención escénica, las tres escenas últimas no constituyen, a mi modo de ver, ningún error dramatúrgico de Valle-Inclán sino que son absolutamente necesarias para conseguir el esperpento. Las tres tienen como función dramática fundamental dinamitar la presunta grandeza trágica de la muerte de Max Estrella, desvalorizar su posible sublimidad, degradarla hasta el ámbito de lo grotesco". (AZNAR SOLER, 2000, p. 353).
}

Eutomia, Recife, 22(1): 201-218, Dez. 2018 
violento: arranca de circunstancias absolutamente banales (borracho, Max muere de frío y de hambre), pasa por una grotesca mutilación del cadáver (se pretende demostrar que el «héroe» no ha muerto de verdad) y termina en la absoluta literarización del personaje (un ente de ficción, el marqués de Bradomín, evoca la muerte de Hamlet tras asistir al entierro de Max.) El resultado es un protagonista que no se mantiene en pie literal y figuradamente: antes que personaje objetivo, es, como él mismo anuncia, «un espectro del pasado». (DOUGHERTY, 2001, p. 19; 703)

Esta propuesta distorsionada, que rompe las expectativas artísticas del receptor, está en consonancia con el arte deshumanizado teorizado por Ortega, y expresado en otro momento importante de la teorización teatral de Valle: el prólogo a Los cuernos de Don Friolera:

-Don Manolito: "Hay que amar, Don Estrafalario: La risa y las lágrimas son los caminos de Dios. Ésa es mi estét ica, y la de usted". -Don Estrafalario: "La mía no. Mi estética es una superación del dolor y de la risa, como deben ser las conversaciones de los muertos, al contarse historias de los vivos". (VALLE-INCLÁN, 2002, p. 993)

El palimpsesto discursivo de Luces de bohemia configura la "estrafalaria" tragedia moderna de Valle, a través de una estética sistemática deformada, mediante la metáfora de los espejos cóncavos de la calle del Gato:

Estoy iniciando un género nuevo, al que llamo "género estrafalario". Ustedes saben que en las tragedias antiguas, los personajes marchaban al dest ino trágico, valiéndose del gesto trágico. Yo en mi nuevo género también conduzco a los personajes al destino trágico, pero me valgo para ello del gesto ridículo. En la vida existen muchos seres que llevan la tragedia dentro de sí y que son incapaces de una actitud levantada, resultando, por el contrario grotescos en todos sus actos. (DOUGHERTY, 1983, p.107-108).

En la estética deformante enunciada en esta escena, asoma la figura pictórica de Goya, a quien este Max/Valle-Inclán atribuye la paternidad del nuevo hallazgo teatral. ${ }^{15}$ La disonancia expresionista del esperpento es la única forma de describir la sociedad absurda de los años 20, al tiempo que sirve para deconstruir las claves discursivas del sistema político, religioso, cultural y las estructuras de poder en la

15 Vid. a este respecto Rubio Jiménez (2006, p. 21-50). 
España primorriverista. Se construye a través de un collage estético de procedencia diversa: tragedia, melodrama o farsa provocan un efecto disonante y distanciado en el horizonte de expectativas del lector/espectador de la época. Según Dougherty (2008, p. 70; 482), Valle alcanza la burla esperpéntica de las instituciones y códigos culturales, a partir de la disonancia que se origina con la superposición y el collage de elementos dispares:

Cabe subrayar dos operaciones en este juego: primero, la inserción en el contexto de la tragedia de elementos ajenos a ella, que crean rupturas con las convenciones del género, mas sin borrar del todo lo trágico. Tragedia, sainete, melodrama, drama calderoniano y farsa de guiñol no se anulan en el ejemplo ofrecido: de repente se abre un espacio liminal en el que todos coinciden en discordia. Segundo, las fronteras del género se abren a valores nuevos, traídos por las "piezas" extrañas venidas de otros géneros o subgéneros teatrales. El valor trágico no desaparece en el esperpento; antes bien, cobra relieve al contrastarse con el hipérbole fatuo del melodrama, con la comicidad frivola del sainete, y con la acción mecánica del guiñol. Al mismo tiempo, sin embargo, lo trágico se impregna del patetismo, la corrosividad y la visualidad grotesca de esos otros géneros, amén de implicarse en la actualidad sociopolítica a la que ellos suelen responder".

Como en una construcción cubista esta superposición de elementos disonantes y diferentes: farsescos, trágicos, grotescos, cómicos generan un pastiche revolucionario tanto artística como lingüísticamente. Como se ha dicho, esta amalgama estética también alcanza a los últimos momentos de Max Estrella, que no dejan de potenciar esta caracterización, ya que su personaje también se pasea por delante de los espejos cóncavos del callejón del Gato, que metaforizan este paseo absurdo y deformante. La paternidad indicada de Goya evidencia la radicalización grotesca y las deudas plásticas del esperpento. También aparece, de manera implícita el sentido trágico de la vida, que según en diversas declaraciones del autor, representaba el Greco. ${ }^{16}$ El patet ismo barroco, parodiado ampliamente en los textos dramát icos de Valle, asoma en la máscara grotesca y trágica de Max. El sustrato serio

\footnotetext{
16 "La emoción suprema del arte en aquellos estros (sic) trágicos en que la vida no es sino una máscara de la muerte" (VALLE-INCLÁN, 1994, p. 48).
} 
y severo del "Viacrucis" del Greco se transfigura en la mueca contraída de un hombre que languidece de frío y borrachera. En los estertores de la muerte balbucea una respuesta, una formulación diferente para expresar esta civilización deformada, grotesca y absurda, concretada en un Madrid, lúcido y mediocre, violento y digno. La ciudad y civilización de los años 20, y a la que Max Estrella pretende poner voz, es hambrienta, absurda y brillante a partes iguales.

\section{Referencias bibliográficas}

\section{a) Ediciones críticas}

VALLE-INCLÁN, Ramón María. Luces de bohemia. Edición de Alonso Zamora Vicente y guía de lectura y glosario de Joaquín del Valle-Inclán Madrid: Espasa Calpe, 2011.

VALLE-INCLÁN, Ramón María. Luces de bohemia. Edición e introducción de Catalina Míguez Vilas. Madrid: Alianza Editorial, $2017 a$.

VALLE-INCLÁN, Ramón María. Luces de bohemia. Edición e introducción de Francisco Caudet Madrid: Cátedra, 2017b.

VALLE-INCLÁN, Ramón María. Luces de bohemia. Edición e introducción de Luis Iglesias Feijoo. Barcelona: Vicens Vives, 2017c.

VALLE-INCLÁN, Ramón María. Luces de bohemia. Edición e introducción de Xaquín Núñez Sabarís. Huelva: Okto contenidos, 2018.

\section{b) Obras citadas}

AZNAR SOLER, Manuel. Luces de bohemia: teoría y práctica del esperpento. In: SANTOS ZAS, Margarita et al. (Org.), Valle-Inclán (1898-1998): Escenarios. Actas Seminario Internacional Sant iago de Compostela noviembre - diciembre, 1998, Santiago de Compostela: Universidade de Santiago de Compostela, 2000, p. 339-360.

. Iluminaciones sobre Luces de bohemia de Valle-Inclán. Sevilla: Renacimiento, 2017.

BARREIRO, Javier. Las opiniones de Valle-Inclán sobre el cine. Una entrevista desconocida. Anales de la literatura española contemporánea, vol. 20, n. 3, P. 503-516, 1995.

CALINESCU, Matei. Cinco caras de la modernidad. Madrid: Editorial Tecnos, 1991.

CARDONA, Rodolfo; ZAHAREAS, Anthony N. Re-Visión del esperpento. Madrid: ADE, 2012. 
DOUGHERTY, Dru (Org.). Un Valle-Inclán olvidado: entrevistas y conferencias. Madrid: Fundamentos, 1983.

. La crisis del personaje en el teatro de Valle-Inclán: Montenegro y Máximo Estrella. Anales de la Literatura Española Contemporánea - Anuario Valle-Inclán I, vol 26, Issue 3, p. 9-693; 27-711, 2011.

. Palimpsestos al cubo: prácticas discursivas de Valle-Inclán. Madrid: Ed. Fundamentos, 2003.

. Valle-Inclán y la tragedia moderna. Anales de la Literatura Española Contemporánea - Anuario Valle-Inclán VIII, vol 33, Issue 3, p. 57-469- 88-500, 2008.

. Destruir es crear: Vestigios de Orfeo en Valle-Inclán. In: SANTOS ZAS, Margarita et al. (Org.). Valle-Inclán y las artes. Santiago de Compostela: Cátedra Valle-Inclán - Universidade de Santiago de Compostela, p. 129-140, 2002.

FERNÁNDEZ, Luis Miguel. Romance de lobos en el cine: ¿un proyecto frustrado de ValleInclán?. Anales de la literatura española contemporánea / Anuario Valle-Inclán, vol. 26, issue 3, p. 783-794, 2001.

LYOTARD, Jean-François. A condição Pós-Moderna, Lisboa: Ed. Gradiva, 1989.

ORTEGA Y GASSET, José. La deshumanización del arte y otros ensayos de estética. Madrid: Espasa Calpe, 1987.

PAZ GAGO, José María; Discurso escénico y cinematográfico en la obra de Valle-Inclán. Cuadrante, n. 21, p. 59-69, 2000.

RUBIO JIMÉNEZ, Jesús. Valle-Inclán, caricaturista moderno. Nueva lectura de Luces de bohemia. Madrid: Editorial Fundamentos, 2006.

SALAÜN, Serge; SERRANO, Carlos. 1900 en España. Madrid: Espasa Calpe, 1991.

SANTOS ZAS, Margarita. La ciudad y su representación literaria: Luces de bohemia, de ValleInclán. Diacrítica, vol. 21.3, p. 171-198, 2007.

VALLE-INCLÁN, Joaquín; VALLE-INCLÁN, Javier del (Org.). Ramón María del Valle-Inclán. Entrevistas, conferencias y cartas. Valencia: Pre-Textos, 1994.

VILLARMEA ÁLVAREZ, María Cristina. Valle-Inclán, entre el oficio y el arte: la profesionalización del escritor en la España de 1900. In: SERRANO ALONSO, Javier; JUAN BOLUFER, Amparo de (Org.). Literatura hispánica y prensa periódica (1875-1931). Actas del 
Congreso Internacional.Lugo. 25-28 de noviembre de 2008. Santiago de Compostela: Universidade de Sant iago de Compostela, 2009, p. 649-664.

ZAMORA VICENTE, Alonso. La realidad esperpéntica. Aproximación a Luces de bohemia. Madrid: Gredos, 1969.

' Professor Associado (Profesor Titular) do Departamento de Estudos Românicos do Instituto de Letras e Ciências Humanas (ILCH) da Universidade do Minho. xnunez@ilch.uminho.pt / http://xaquinnunez.com/ 